\title{
A Study on Sibling Relationships, Life Satisfaction and Loneliness Level of Adolescents
}

\author{
F.Selda Öz Soysal \\ Correspondence: F.Selda Öz Soysal, Buca Faculty of Education, Dokuz Eylül University, İzmir, 35150, Turkey.
}

Received: December 9, 2015 Accepted: December 23, 2015 Online Published: January 16, 2016

doi:10.11114/jets.v4i4.1240

URL:http://dx.doi.org/10.11114/jets.v4i4.1240

\begin{abstract}
The purpose of this study was to examine the relation between sibling relationships, life satisfaction, and the loneliness level of adolescents with regard to gender, order of birth, and sibling dyads. The study group consisted of 382 (209 female, 173 male) students in total, who were studying at high schools (regular high school, vocational high school, Anatolian High School, private colleges) selected from Karşıyaka District in the city of İzmir, Turkey. The data collection tools used were the Life Span Sibling Relationship Scale, Life Satisfaction Scale, and Ucla Loneliness Scale III. The multivariate analysis of variance (MANOVA) was used for the analysis of data. The results from the research demonstrated that gender, birth order, and sibling dyads led to significant differences in life satisfaction, level of loneliness, and sibling relationships. In line with the results obtained from the research, it could be recommended that sibling relationships in the Turkish culture should be examined in terms of various age groups and different variables, and their psychosocial consequences should be subject to research.
\end{abstract}

Keywords: adolescence, sibling relationships, life satisfaction, loneliness

\section{Introduction}

As suggested by Voorpostel and Van der Lippe (2007), sibling relationships can be one of the most long-lasting and enduring relationships of an individual. Recent research has focused on quite a number of sibling relationship characteristics, as this particular relationship could be a source for support, solidarity, companionship, and well-being (Bedford, 1995). On the other hand, sibling relationships, as suggested by Connidis (2007), can also provide grounds for competition, conflict, and ambivalence. Dunn (2002) emphasized; three important aspects of sibling relationships: The depth and demonstration of both positive and adverse emotions during childhood and adolescence; the closeness of the siblings, often a source of either conflict or support; and the variance of the relationships based on individual differences of the siblings, some of whom demonstrate positive feelings and affection, while others show hostility and/or aggression or remain ambivalent.

The majority of siblings often spend more time with each other than with anyone else (Sanders, 2004). During childhood, siblings are a fundamental part of most children's social worlds. Emotional ties between siblings are strong, either intensely positive or negative. Siblings can be playmates, watchers, support providers, or sources of annoyance (Furman \&Giberson, 1995). In particular, during early childhood, conflict surrounding property ownership (Ross, 1996) and rivalry for parents' attention (Teti, 2002) characterize this relationship. As siblings grow up, their relationships go through developmental transformations and turn out to be more egalitarian and more symmetrical (Buhrmester \& Furman, 1990). Adolescents seek to develop their own identity, detaching themselves emotionally from parents and showing growing interest in the wider world, friends, and romantic partners. With this development, interest in their siblings and their common activities may drop (Dunn, Slomkowski, Beardsall \& Rende, 1994), accompanied by a decline in both positive and negative interactions (Buhrmester \& Furman, 1990). Cole and Kerns (2001) demonstrated that early adolescents experienced less companionship and fewer conflicts with their siblings, than did younger children, and thus, their relationships were less intensive (Buhrmester \& Furman, 1990). Twelfth grade students reported that they felt more distant from, and were spending less time with, their siblings, and they felt less affection, intimacy, and caring from their siblings than did third, sixth, and ninth grade students (Buhrmester \& Furman, 1990). The decline in the intensity of the relations was also reflected through fewer incidents of dispute, antagonism, and rivalry, and the diminished relevance of power and status issues (Buhrmester \& Furman, 1990). However, newer findings indicated that, although the distance between the siblings grew and their common activities decreased, their emotional attachment to each other remained moderately strong throughout adolescence (Cole \& Kerns, 2001). In their longitudinal study, Updegraff, McHale, and 
Crouter (2002) demonstrated that toward late adolescence, participants experienced an increase in intimacy with their siblings. Furthermore, Tucker, McHale, and Crouter (2001) suggested that 13- and 16-year-olds generally described their older siblings as being supportive in terms of social and academic matters, as well as in family issues. Overall, the increased independence and emotional detachment from the family during adolescent years was also reflected in the growing distance between the siblings (Buhrmester \& Furman, 1990). Yet evidence existed that, despite this increased distance with age, intimacy, and caring between adolescent siblings remained and persevered.

In terms of gender, females were perceived to be more involved in intimate sibling relationships than males, and the relationship between sisters was described as the most intensive bond among sibling relations (Dunn et al., 1994). Hetherington (1988) demonstrated that boys consistently had more negative relationships with their siblings and tended to be more aggressive toward their siblings than girls (Milevsky, 2011). Females were perceived to receive more advice, feel more satisfied with support, and be more deeply influenced by siblings than were males (Tucker, Barber \& Eccles, 1997). Female siblings were found to have a higher potential to produce emotionally supportive outcomes during the years of adolescence (Howe, Aquan-Assee, Bukowski \& Rinaldi, 2001).

In studies performed on siblings during childhood and adolescent phases, sibling gender constellation were also found to influence sibling relationships, and same sex sibling dyads reported higher levels of intimacy and less hostility than opposite-sex dyads (Buhrmester \& Furman, 1990). Sister-sister dyads were found to have the highest levels of warmth, intimacy and closeness (Buhrmester \& Furman, 1990; Dunn.et al., 1994; Riggio, 2000) and were different from other sibling gender constellations it was demonstrated that sisters felt most similar and served as close companions to each other (Buhrmester \& Furman, 1990). In contrast, dyads of boy siblings reported less caring, less exchange of intimacy, and less coping resolution than dyads of girl siblings (Cole \& Kerns, 2001).

As Benin and Johnson (1984) underlined, older siblings possessed a greater opportunity to influence younger siblings because they spent more than twice as much time with their siblings than with their parents. Younger siblings benefited from the guidance and support offered by older siblings and tended to maintain a higher level of intimacy with them (Oliva \& Arranz, 2005).In a study conducted with adolescents, Milevsky (2005) reported that older siblings experienced less conflict with their youngers. Additionally, Dolgin and Lindsay (1999) reported that younger siblings sought emotional support and advice from older siblings, however, older siblings were engaged more with teaching younger siblings. Researchers noted that adolescents who reported higher levels of sibling relationship quality; also reported higher levels of emotional support from their sibling (Alfaro \& Umana-Taylor, 2010; Yeh \& Lempers, 2004).

Sibling relationship quality during adolescence was shown to have an influence on developmental outcomes. Negative sibling relationships were associated with adolescents' risky behavior, adjustment problems, school problems, bullying (Bank, Burraston \& Snyder, 2004; Stocker, Burwel \& Briggs, 2002), antisocial behaviors (Criss \& Shaw, 2005; Fagan \& Najman, 2003) and substance use ( Fagan \& Najman, 2005; Scholte, Poelen, Willemsen, Boomsma \& Engels, 2008; Slomkowski, Rende, Novak, Lloyd-Richardson\& Niaura, 2005). Sibling conflicts were also associated with both internalizing (fear, inhibition, and overcontrol) and externalizing behaviors (aggression, antisocial behavior, and undercontrol) (Buist, Dekovic \& Prinzie, 2013; Natsuaki, Ge, Reiss \& Neiderhiser, 2009; Vogt Yuan, 2009). According to Stocker (2002), children growing up with a discordant sibling relationship could experience despair as they felt guilty for struggling and could fear that the discordance would never end. A number of studies also indicated that a more discordant sibling relationship was more likely to lead to increases in depressive symptoms and self-harming (Brody, 1998; Bowes, Wolke, Joinson, Lereya \& Lewis, 2014; Richmond, Stocker \& Rienks 2005).

On the other hand, sibling relationships could provide natural environment for children to learn to develop relationships with peers, pay attention to other's perspectives and feelings, and develop significant skills like anger management, problem solving, and conflict resolution (Brody, 2004). Positive sibling relationships were associated with numerous benefits related to social, emotional and health related development throughout childhood and adolescence. These benefits included, but were not limited to, higher peer competence (Kim, McHale, Crouter \& Osgood, 2007), prosocial behavior (Brody, Kim, Murry \& Brown, 2003; Whiteman, McHale \& Crouter, 2007), academic engagement (Bouchey, Shoulberg, Jodl \& Eccles, 2010), personal achievement (Wheeler, 2012), healthy emotion regulation (Kennedy \& Kramer, 2008), high level of self-regulation (Padilla-Walker, Harper \& Jensen, 2010), better adjustment (Noller, 2005; Pike, Coldwell \& Dunn, 2005), prosocial behavior (Brody, Kim, Murry \& Brown 2003; Whiteman, McHale \& Crouter, 2007), empathy (Tucker, Updegraff, McHale \& Crouter, 1999) . Positive sibling relationships could also deter depression (Kim, et al., 2007), juvenile misdeeds (Widmer \& Weiss, 2000), and other adversity (Conger \& Conger, 2002). In addition to direct effects, sibling support could also buffer the impacts of distressful life events on internalization problems, as; children with supportive siblings were reported to experience fewer depressive symptoms after distressing life events than children in unsupportive sibling relationships (Gass, Jenkins \& Dunn, 2007). 


\subsection{The Aim of the Study}

In accordance with the above statements, sibling relationships are assessed as important for adolescents in terms of psychosocial implications. Research conducted abroad indicates that the quality of sibling relations among adolescents is significantly related to psychological well-being (Milevsky, 2003; Milevsky \& Levitt, 2005; Oliva \& Arranz, 2005; Yeh\&Lempers, 2004). The literature in Turkey mainly includes studies on relationships of individuals with disabled siblings (Ahmetoğlu, 2004; Aksoy \& Berçin-Yıldırım, 2008; Apalaçi, 1996; Atasoy, 2002; Bozbey-Akalın, 2005; Erden \& Akçakın, 2001; Girli, 1995; Küçüker, 1997; Onat-Zoylan, 2005). However, no studies have been found that examine the quality and the psychosocial consequences of sibling relationships of adolescents who have experienced normal development. The purpose of this study is to examine the relationship between sibling relations, life satisfaction, and loneliness levels, depending on gender, order of birth, and sibling dyads among adolescents.

\section{Method}

\subsection{Research Design}

Quantitative research method was used in this study.

\subsection{Participants}

The study group consisted of 382 students (209 females and 173 males) attending high schools chosen with general high school, vocational high school, Anatolian High School, private high school in Karşıyaka District of Izmir Province during 2013-2014 education year, who volunteered to fill out the scale. The participants were $9^{\text {th }}$ grade $(n=119), 10^{\text {th }}$ grade $(\mathrm{n}=139)$ and $11^{\text {th }}$ grade $(\mathrm{n}=124)$ students. Their ages ranged from 15 to17 $(\mathrm{M}=16.01, \mathrm{SD}=.798) .77$ participants were female and older siblings; 47 were female and younger siblings. 72 were male and older siblings. 101 were male and younger siblings. 134 siblings constituted female dyads, 124 siblings constituted male dyads, and 124 siblings constituted female-male dyads. All siblings were full biological siblings and came from intact families. Especially 12th graders of vocational high schools don't attend their school because they intern. The $12^{\text {th }}$ classes were not included in the study in order to provide equality on a class level in all schools.

\subsection{Procedure}

The study was conducted in the classrooms after obtaining permission from the school administrators. Students were informed about the goal of the research and voluntary participation. All of the students volunteered to participate in the study. It took 40 to 45 minutes for the students to complete the scales. Data collection was undertaken by the author.

\subsection{Measures}

Personal information form: The information regarded the age, gender and grade of students as well as their birth order, ages of siblings and genders of siblings was collected by a personal information form designed by the researcher.

Life Span Sibling Relationship Scale: The scale was developed by Riggio (2000). LSRS consists of 48 items in total, including 40 positive and 8 negative. Each item is a Likert type scale, scored between 1 (strongly disagree) and 5 (strongly agree). During calculation of the scores of, the negative items are reverse-scored. The scores that can be received from the scale range between 48 and 240. High scores indicate good sibling relationships while low scores indicate sibling relationships. The validity and reliability of the scale was tested by Öz (2015) and the Cronbach alpha coefficient of the scale was found as .951 .

Ucla Loneliness Scale III: The scale was developed by Russel, Peplau and Ferguson in 1996. UCLA-III consists of 20 items in total, including 11 positive and 9 negative. Each item is a Likert type scale, scored between 1 (never) and 4 (always). During calculation of the loneliness score, the negative items are reverse-scored. The scores that can be received from the scale range between 20 and 80. High scores indicate loneliness and low scores indicate non-loneliness. The validity and reliability of the scale in Turkey was tested by Durak and and Şenol-Durak (2010) and the Cronbach alpha coefficient of the scale was found as .90 .

Life Satisfaction Scale: The scale was developed by Diener, Emmons, Laresen and Griffin (1985). It was adapted to Turkish language by Köker (1991). The scale consists of five items related to life satisfaction. Each item is answered according to a 7-point system 1not suitable at all 7very suitable). The scale aim at measuring general life satisfaction fits all ages from adolescents to adults. High scores received from the scale indicate a high level of life satisfaction. The sale was adapted to Turkish language by Köker (1991). A new study carried out in Turkey suggests that the psychometric properties of the life satisfaction scale are more satisfactory in three different and independent samples (Durak, Şenol-Durak \& Gençoz, 2010). The Cronbach alpha coefficient was found as .73 in this study.

\subsection{Data Analysis}

The study examined, through multivariate analysis of variance, whether scores in life span sibling relationship, life satisfaction, and loneliness differ depending on gender, selected sibling, and birth order. When the assumptions of 
MANOVA analysis are tested, it was found out through skewness and kurtosis coefficients that scores of dependent variables displayed a single-variable normal distribution, and it was observed through Mahalanobis distances that the scores did not differ from multiple-variable normal distribution. It was also revealed that distributions of dependent variables did not display and extreme deviation from single-dimension and multiple-dimension normal distribution. A linear relationship was found between dependent variables by examining scatter plots. This situation demonstrates that dependent variables selected in the study meet the assumptions of MANOVA analysis.

\section{Results}

Table 1.Descriptive Statistics of Scores of Life Span Sibling Relationship, Life Satisfaction, and Loneliness Scales by Gender, Sibling Dyad and Birth Order

\begin{tabular}{cccccccccc}
\hline & & & \multicolumn{2}{c}{ Life Span Sibling } & \multicolumn{2}{c}{ Life } \\
Gender & Sibling & Birth & \multicolumn{4}{c}{ Relationship } & \multicolumn{2}{c}{ Satisfaction } & \multicolumn{2}{c}{ Loneliness } \\
& Dyad & Order & $\mathrm{n}$ & $\bar{x}$ & $\mathrm{~s}$ & $\bar{x}$ & $\mathrm{~s}$ & $\bar{x}$ & $\mathrm{~s}$ \\
\hline Female & Female & First & 57 & 186.58 & 33.39 & 26.40 & 6.64 & 22.70 & 12.80 \\
& & Second & 77 & 201.19 & 26.97 & 29.21 & 5.34 & 16.60 & 11.90 \\
& Male & First & 28 & 149.43 & 46.69 & 21.57 & 8.27 & 27.96 & 12.84 \\
& & Second & 47 & 122.66 & 52.22 & 16.77 & 8.13 & 36.47 & 14.12 \\
Male & Female & First & 17 & 97.82 & 44.88 & 14.82 & 8.00 & 40.47 & 12.55 \\
& & Second & 32 & 141.22 & 46.93 & 19.94 & 7.51 & 29.06 & 12.11 \\
& \multirow{2}{*}{ Male } & First & 55 & 185.04 & 38.35 & 26.85 & 5.77 & 20.20 & 10.73 \\
& & Second & 69 & 199.81 & 33.39 & 29.42 & 4.82 & 15.19 & 9.44 \\
\hline
\end{tabular}

The relationships between the variances used in the study were calculated with Person Moment Correlation coefficient. It was found that the correlation coefficient of life span sibling relationships and life satisfaction was $r=.921$, the relation between life span sibling relationships and loneliness was $r=-.835$ and the relation between life satisfaction and loneliness was $\mathrm{r}=-.903$. It was decided to carry out manova analysis instead of regression analysis because of the correlation coefficients between the variances were high. In the table below, manova results are given.

Table 1. MANOVA Results in respect of Effects of Gender, Selected Sibling and Birth Order on Scores of Life Satisfaction, Loneliness and Life Span Sibling Relationship Scales

\begin{tabular}{|c|c|c|c|c|c|}
\hline & $\begin{array}{l}\text { Source } \\
\end{array}$ & df & $\mathrm{F}$ & $\eta$ & $\mathrm{p}$ \\
\hline \multirow{3}{*}{ Gender } & Life Span Sibling Relationship Total & 1 & 4.348 & 0.107 & .038 \\
\hline & Life Satisfaction Total & 1 & 1.197 & 0.056 & .275 \\
\hline & Loneliness Total & 1 & .102 & 0.016 & .750 \\
\hline \multirow{3}{*}{ Sibling Dyad } & Life Span Sibling Relationship Total & 1 & 3.052 & 0.090 & .081 \\
\hline & Life Satisfaction Total & 1 & 2.329 & 0.079 & .128 \\
\hline & Loneliness Total & 1 & 3.029 & 0.090 & .083 \\
\hline \multirow{3}{*}{ Birth Order } & Life Span Sibling Relationship Total & 1 & 9.917 & 0.161 & .002 \\
\hline & Life Satisfaction Total & 1 & 7.949 & 0.144 & .005 \\
\hline & Loneliness Total & 1 & 11.920 & 0.176 & .001 \\
\hline \multirow{3}{*}{ Gender * Sibling dyad } & Life Span Sibling Relationship Total & 1 & 236.982 & 0.622 & .000 \\
\hline & Life Satisfaction Total & 1 & 191.451 & 0.581 & .000 \\
\hline & Loneliness Total & 1 & 133.299 & 0.512 & .000 \\
\hline \multirow[b]{2}{*}{ Sibling dyad $*$ Birth order } & Life Span Sibling Relationship Total & 1 & 17.270 & 0.209 & .000 \\
\hline & Life Satisfaction Total & 1 & 14.063 & 0.190 & .000 \\
\hline & Loneliness Total & 1 & 17.270 & 0.210 & .000 \\
\hline \multirow{4}{*}{ Gender * Birth order } & Life Span Sibling Relationship Total & 1 & 17.013 & 0.208 & .000 \\
\hline & Life Satisfaction Total & 1 & 12.536 & 0.180 & .000 \\
\hline & Loneliness Total & 1 & 13.739 & 0.188 & .000 \\
\hline & & 1 & 17.013 & 0.208 & .000 \\
\hline \multirow{3}{*}{ Error } & Life Span Sibling Relationship Total & 375 & & & \\
\hline & Life Satisfaction Total & 375 & & & \\
\hline & Loneliness Total & 375 & & & \\
\hline
\end{tabular}

As shown in Table 2, as a result of the analyses based on gender, a significant difference was observed only in the scores of life satisfaction between females and males, Wilk's $\Lambda=.978, \mathrm{~F}(3.373)=0.04, \mathrm{p}<0.05$. There was no significant difference in total scores of dependent variables in terms of sibling dyad, Wilk's $\Lambda=.99, \mathrm{~F}(3.373)=0.298$, $\mathrm{p}>0.05$, whereas, a significant difference was found between average scores of all dependent variables by birth order, Wilk's $\Lambda=.964$, $\mathrm{F}(3.373)=0.04, \mathrm{p}<0.05$.

When the interactions of independent variables were examined, the interaction effect of gender and sibling dyad were observed to be significant, Wilk's $\Lambda=.611, \mathrm{~F}(3.373)=0.00, \mathrm{p}<0.05$. The interaction effect of gender and sibling dyad on life span sibling relationships of the students was observed to be significant $F(1.375)=236.982$, $p<0.01$. The effect size was observed to be large for the scale $(\eta=0.62)$ (Leech et al.) When female students had siblings of the same gender, it was 
observed that their positive attitude toward sibling relationship increased, while it decreased when they had siblings of the opposite gender. Similarly, when male students had siblings of the same gender, it was observed that their positive attitude toward sibling relationship increased, while it decreased when they had siblings of the opposite gender.

The interaction effect of gender and sibling dyad on life satisfaction scores of the students was revealed to be significant $F(1.375)=191.451, p<0.01$. The effect size was observed to be high for the scale, $(\eta=0.58)$ (Leech et al., 2007). In this case, when female students had siblings of the same gender, it was observed that their life satisfaction score increased, while it decreased when they had siblings of the opposite gender. Similarly, when male students had siblings of the same gender, it was observed that their life satisfaction score increased, while it decreased when they had siblings of the opposite gender.

The interaction effect of gender and sibling dyad on loneliness scores of the students was found out to be significant $F(1.375)=133.299, p<0.01$. The effect size was found to be large for the scale, $(\eta=0.51)$ (Leech et al., 2007). In this case, female students were observed to have lower levels of loneliness when they had siblings of the same gender, and higher levels of loneliness when they had siblings of the opposite gender. Male students were observed to have higher levels of loneliness when they had siblings of the same gender, and lower levels of loneliness when they had siblings of the opposite gender. Among averages of dependent variables, the interaction effect of the sibling dyad and birth order on life span sibling relationship scores was found significant, Wilk's $\Lambda=.949, \mathrm{~F}(3.373)=0.00, \mathrm{p}<0.05$. The interaction effect of sibling dyad and birth order on life span sibling relationship score of the students was discovered to be significant, $F(1.375)=17.098, p<0.01$. The effect size was observed to be low for the scale, $(\eta=0.21)$ (Leech et al., 2007). Students who were first in birth order and who had female siblings were observed to have a more positive attitude toward sibling relations, compared to students who were second in birth order and had female siblings. On the other hand, students who were the first in birth order and had male siblings were observed to have a less positive attitude toward sibling relations, compared to students who were second in birth order and had female siblings.

The interaction effect of sibling dyad and birth order on life satisfaction score of the students was revealed to be significant, $F(1.375)=14.063, p<0.01$. The effect size was observed to be low for the scale, $(\eta=0.19)$ (Leech et al., 2007). Students who were first in birth order and had female siblings had higher life satisfaction, compared to students who were second in birth order and had female siblings. Students who were first in birth order and had male siblings had lower life satisfaction, compared to students who were second in birth order and who had male siblings.

The interaction effect of sibling dyad and birth order on loneliness scores was discovered to be significant $F(1.375)=17.270, p<0.01$. The effect size was observed to be low for the scale, $(\eta=0.21)$ (Leech et al., 2007). Students who were first in birth order and had female siblings were observed to experience lower levels of loneliness, compared to those who were second in birth order and had female siblings. On the other hand, students who were first in birth order and had male siblings were observed to experience higher levels of loneliness, compared to those who were second in birth order and had male siblings.

The interaction effect of gender and birth order on averages of dependent variables was observed to be significant, Wilk's $\Lambda=.949, \mathrm{~F}(3.373)=0.00, \mathrm{p}<0.05$. The interaction effect of gender and birth order on life span sibling relationships of the students was revealed to be significant $\mathrm{F}(1.375)=17.013$, $\mathrm{p}<0.01$. The effect size was observed to be low for the scale, $(\eta=0.21)$ (Leech et al., 2007). Female students who were first in birth order were observed to have less positive attitudes toward sibling relations compared to female students who were second in birth order. As for male students, no significant difference was observed in terms of the effect of birth order on life span sibling relations.

The interaction effect of gender and birth order on life satisfaction scores was found out to be significant $F(1.375)=12.536$, $p<0.01$. The effect size was observed to be low for the scale, $(\eta=0.18)$ (Leech et al., 2007). Female students who were first in birth order were observed to have lower life satisfaction, compared to female students who were the second in birth order. As for male students, no significant difference was observed in terms of the effect of birth order on life satisfaction.

The interaction effect of gender and birth order on the level of loneliness was discovered to be significant $F(1.375)=13.739, p<0.01$. The effect size was observed to be low for the scale, $(\eta=0.19)$ (Leech et al., 2007). Female students who were first in birth order were observed to have higher level of loneliness, compared to female students who were second in birth order. As for male students, no significant difference was observed in terms of the effect of birth order on loneliness.

\section{Discussion}

When the statistical data obtained from the research were analyzed, gender, birth order, and sibling dyad (sisters, brothers, and siblings of opposite gender) were found to create significant difference in life satisfaction, loneliness and sibling relationships. Students who had siblings of the same gender were observed to have more positive attitudes toward sibling relationships than those who had siblings of the opposite gender. This result was parallel to the results of previously 
performed researches (Oliva \& Arranz, 2005). Buhrmester and Furman (1990) reported that siblings of the same gender were closer to their siblings than siblings of the opposite gender. According to Tucker, Barber and Eccles (1997), siblings of dyads of the same gender were more open toward and supportive for each other and much more influenced by each other. On the other hand, female students who had siblings of the same gender had lower levels of loneliness, while male students who had siblings of the opposite gender had lower levels of loneliness. In his research on sibling relationships, Milevsky (2011) stated that adolescent females cared much more about and behaved in a more companionable manner toward their siblings than adolescent males. The result obtained from this research could be interpreted that having female siblings decreased the level of loneliness.

Another finding of the research was that students who were first in birth order and who had female siblings enjoyed higher levels of life satisfaction and positive attitude toward sibling relationships, and lower levels of loneliness than students who were second in birth order and had female siblings. On the other hand, students who were first in birth order and had male siblings were observed to have lower levels of life satisfaction and positive attitude toward sibling relationships, and higher levels of loneliness compared to those who were second in the birth order and had male siblings. In their research, Tucker et al. (2001) revealed that sisters who were first or second in the birth order supported their siblings much more than brothers who were first or second in the birth order. Furthermore, they reported that the elder sisters supported their siblings much more in matters related to social life.

Another finding of the research was that female students who were first in birth order had lower life satisfaction, less positive attitude toward sibling relationships, and higher levels of loneliness than female students who were second in birth order. As for male students, no significant difference was observed between them in terms of the effect of birth order on life satisfaction and attitude toward sibling relationships. Oliva and Arranz (2005) stated that younger siblings received much more emotional support and intimacy from their elder siblings. Buhrnmaster (1992) reported that younger siblings admired their elder siblings, while elder siblings felt much more jealousy and hostile feelings toward the younger siblings. This result obtained from the research in relation to female students paralleled the results of the research by Olivia Arranz (2005) and Buhrnmaster (1992), but not the results obtained in relation to male students. According to Cicirelli (1994), certain roles were expected depending on the birth order of siblings. For example, the elder sibling was expected to be responsible for doing the chores and taking care of the younger siblings. The elder child of the family was more likely to substitute the parent as the age difference increased in siblings. The elder sibling not only took care of the younger ones, but also helped them with their education and socialization. This result obtained from the research could be interpreted as that the elder female sibling had more duties and responsibilities within the family and received less support, and as such, they had less life satisfaction, less positive attitude toward their siblings, and higher levels of loneliness.

This research was subject to a number of limitations. First, the study group was made of students who had one sibling only. The relation between the elder and the younger sibling was examined in terms of life satisfaction and level of loneliness. The sibling in the middle was left out of the scope. Riggio (2006) suggested that in wider families, the probability of interaction between siblings was higher; thus siblings could be closer to each other. Future studies that investigate relations between higher numbers of siblings in wider families would provide more information on both siblings in the middle and sibling relations in wider families. Another limitation is the fact that the age difference between the siblings was not taken into account. Milevsky (2005) indicated age difference as an important factor in understanding the relationship between siblings. It would be meaningful to take into account the age difference between siblings in future studies. Furthermore, the research group consisted of students who had full biological siblings and came from intact families. Therefore, the results of the study could only be generalized for those adolescents who had full biological siblings and who came from intact families (Intact families refer to families in which both biological parents are present in the home). And finally, this research was conducted as a sectional study, i.e., for the high schools in Karşıyaka District of İzmir Province. In order to generalize the results of the study for Turkish culture, research should be conducted of sampling groups with participants from different regions of Turkey that demonstrate different cultural features.

In line with the results obtained from the research, it was observed that the quantity of research on the quality of sibling relationships in Turkey was inadequate. Therefore, it could be recommended that sibling relationships in Turkish culture should be examined in terms of various age groups and different variables, and their psycho social consequences should be subject to research. Moreover, developmental results of sibling relationships could be examined through longitudinal studies. Studies on the relation between sibling relationships and family relationships under various parenthood styles could be recommended. Additionally study on sibling relationships could provide an impetus for guidance to services by psychological advisors and family advisors on strengthening relationships with siblings, which is the most important source of social support for their clients. 


\section{References}

Aksoy, A. B., \& Berçin-Yıldırım, G. (2008). A study of the relationships and acknowledgement of non-disabled children with disabled siblings Educational Sciences: Theory \& Practice, 8(3), 751-779.

Alfaro, E., \& Umana-Taylor, A. (2010). Latino adolescent's academic motivation: The role of siblings. Hispanic Journal of Behavioral Sciences, 32(4), 549-570.http://dx.doi.org/10.1177/0739986310383165

Apalaçi, V. (1996). Psychological adjustment and sibling relationships of older brothers and sisters of children with pervasive developmental disorders. Unpublished MS Thesis, Boğaziçi Üniversitesi, Sosyal Bilimler Enstitüsü, İstanbul.

Atasoy, S. (2002). The examination of the relationship between the cognitive functions among high functioning autistic children . Unpublished MS Thesis, Ege Üniversitesi Sosyal Bilimler Enstitüsü, İzmir.

Bank, L., Burraston, B., \& Snyder, J. (2004). Sibling conflict and ineffective parenting as predictors of adolescent boys' antisocial behavior and peer difficulties: Additive and interactional effects .Journal of Research on Adolescence, 14, 99-125.http://dx.doi.org/10.1111/j.1532-7795.2004.01401005.x

Bedford, V. H. (1995). Sibling relationships in middle adulthood and old age. In R.M. Benin, M.\& Johnson, D. (1984). Sibling similarities in educational attainment: A comparison of like-sex and cross-sex sibling pairs. Sociology of Education, 57, 11-21.

Bouchey, H. A., Shoulberg, E. K., Jodl, K. M., \& Eccles, J. S. (2010). Longitudinal links between older sibling features and younger siblings' academic adjustment during early adolescence. Journal of Educational Psychology, 102, 197-211. http://dx.doi.org/10.1037/a0017487

Bowes, L., Wolke, D., Joinson, C., Lereya, S. T., \& Lewis, G. (2014). Sibling bullying and risk of depression, anxiety, and self-harm: A prospective cohort study. Pediatrics, 134(4), 1-8 .http://dx.doi.org/10.1542/peds.2014-0832d.

Bozbey-Akalın, A . (2005) .Social skills and sibling relations of elder sisters and brothers of children with attention deficit and hyperactivity disorder. Unpublished MS Thesis, Çukurova Üniversitesi, Sosyal BilimlerEnstitüsü, Eğitim Bilimleri Ana Bilim Dalı. Adana.

Brody, G. H. (1998). Sibling relationship quality: Its causes and consequences. Annual Review of Psychology, 49, 1-24. http://dx.doi.org/10.1146/annurev. psych.49.1.1

Brody, G. H. (2004). Siblings' direct and indirect contributions to child development. Current Directions in Psychological Science, 13, 124-126. http://dx.doi.org/10.1111/j.0963-7214.2004.00289.x

Brody, G. H., Kim, S., Murry, V. M., \& Brown, A. C. (2003). Longitudinal direct and indirect pathways linking older sibling competence to the development of younger sibling competence. Developmental Psychology, 39, 618-628. http://dx.doi.org/10.1037/0893-3200.19.2.305

Buhrmester, D. (1992). The developmental courses of sibling and peer relationships. In F.Boer \& J. Dunn (Eds.), Children's sibling relationships: Development and clinical issues. Hillsdale, NJ: Lawrence Erlbaum.

Buhrmester, D., \& Furman, W. (1990). Perceptions of sibling relationships during middle childhood and adolescence. Child Development, 61, 1387-1398. http://dx.doi.org/10.1111/j.1467-8624.1990.tb02869.x

Buist, L. K., Deković, M., \& Prinzie, P. (2013). Sibling relationship quality and psychopathology of children and adolescents: A meta-analysis. Clinical Psychology Review, 33, 97-106. http://dx.doi.org/10.1016/j.cpr.2012.10.007.

Cicirelli, V. G. (1994). Sibling relationships in cross-cultural perspective. Journal of Marriage and the Family, 56, 7-20.

Cole, A., \& Kerns, K. A. (2001). Perceptions of sibling qualities and activities of early adolescents. Journal of Early Adolescence, 21, 204-226. http://dx.doi.org/10.1177/0272431601021002004

Conger, R., \& Conger, K. (2002). Resilience in Midwestern families: Selected findings from the first decade of a prospective, longitudinal study. Journal oMarriage and Family, 64(2), 361-373.

Connidis, I. A. (2007). Negotiating inequality among adult siblings: Two case studies. Journal of Marriage and Family, 69, 482-499. http://dx.doi.org/10.1111/j.1741-3737.2007.00378.x

Criss, M. M., \& Shaw, D. S. (2005). Sibling relationships as contexts for delinquency training in low-income families. Journal of Family Psychology, 19, 592-600. http://dx.doi.org/10.1037/0893-3200.19.4.592

Dolgin, K. G., \& Lindsay, K. R. (1999). Disclosure between college students and their siblings. Journal of Family Psychology, 13, 393-400. http://dx.doi.org/10.1037/0893-3200.13.3.393 
Dunn, J. (2002). Sibling relationships. In P.K. Smith \& C.H. Hart (Eds.), Blackwell handbook of childhood social development(pp. 223-237).

Dunn, J., Slomkowski, C., Beardsall, L., \& Rende, R. (1994). Adjustment in middle childhood and early adolescence: Links with earlier and contemporary sibling relationships. Journal of Child Psychology and Psychiatry, 35, 491-504. http://dx.doi.org/10.1111/j.1469-7610.1994.tb01736.x

Durak, M., \& Senol-Durak, E. (2010). Psychometric qualities of the UCLA loneliness scale-version 3 as applied in Turkish culture. Educational Gerontology, 36(10-11), 988-1007. http://dx.doi.org/10.1080/03601271003756628

Durak, M., Senol-Durak, E., \& Gencoz, T. (2010). Psychometric properties of the satisfaction with life scale among Turkish university students, correctional officers, and elderly adults. Social Indicators Research, 99(3), 413-429. http://dx.doi.org/10.1007/s11205-010-9589-4

Erden, G., \& Akçakın, M. (2001). Patterns of behavioral problems and personality characteristics of autistic children and their siblings. Çocuk ve Gençlik Ruh Sağlı̆̆ı Dergisi, 8(3), 145-155.

Experiences: Developmental patterns and relationship linkages. Social Development, 11, 182-204. http://dx.doi.org/10.1111/1467-9507.00194

Fagan, A. A., \& Najman, J. M. (2003). Sibling influences on adolescent delinquent behavior: An Australian longitudinal study. Journal of Adolescence, 26, 546-558. http://dx.doi.org/10.1016/S0140-1971(03)00055-1.

Fagan, A. A., \& Najman, J. M. (2005). The relative contributions of parental and sibling substance use to adolescent tobacco, alcohol, and other drug use. Journal of Drug Issues, 35, 869-884. http://dx.doi.org/10.1177/002204260503500410

Furman, W., \& Giberson, R. S. (1995). Identifying the links between parents and their children 's sibling relationships. In S. Shulman (Ed.), Close relationships and socioemotional development, 7, 95-108.

Gass, K., Jenkins, J., \& Dunn, J. (2007). Are sibling relationships protective? A longitudinal study. Journal of Child Psychology and Psychiatry, 48, 167-175. http://dx.doi.org/10.1111/j.1469-7610.2006.01699.x

Girli, A. (1995). Determination of acceptance leveles of mentally normal children towards mentally discorded siblings. Unpublished MS Thesis, Dokuz Eylül Üniversitesi, İzmir.

Howe, N., Aquan-Assee, J., Bukowski,W. M., \& Rinaldi, C. M. (2001). Siblings as confidants: Emotional understanding, relationship warmth, and sibling self- disclosure. Social Development, 10, 439-454. http://dx.doi.org/10.1111/1467-9507.00174

Kennedy, D. E., \& Kramer, L. (2008). Improving emotion regulation and sibling relationship quality: The more fun with sisters and brothers program. Family Relations, 57, 567-578.

http://dx.doi.org/10.1111/j.1741-3729.2008.00523.x

Kim, J. Y., McHale, S. M., Crouter, A. C., \& Osgood, D. W. (2007). Longitudinal linkages between sibling relationships and adjustment from middle childhood through adolescence. Developmental Psychology, 43(4), 960-973 .http://dx.doi.org/10.1037/0012-1649.43.4.960

Küçüker, S. (1997). The Effects of an informational counseling program on nonhandicapped siblings knowledge level about mental disability and attitudes toward their brothers or sisters with mental disabilities. Unpublished PhD Thesis, Ankara Üniversitesi, Ankara.

Leech, N., Barrett, K., \& Morgan, G. A. (2007). SPSS for Intermediate Statistics: Use and Interpretation, ThirdEdition: Taylor \& Francis.

Milevsky, A. (2003). Sibling support in preadolescence and adolescence. Paper presented at the meeting ofSociety for Research in Child Development,Tampa.

Milevsky, A. (2005). Compensatory patterns of sibling support in emerging adulthood: Variations in loneliness, self-esteem, depression and life satisfaction. Journal of Social and Personal Relationships, 22(6), 743-755. http://dx.doi.org/10.1177/0265407505056447.

Milevsky, A. (2011). Sibling relationships in childhood and adolescence: Predictors and outcomes. New York: Columbia University Press.

Milevsky, A., \& Levitt, M. J. (2005). Sibling support in early adolescence: Buffering and compensation across relationships. European Journal of Developmental Psychology, 2, 299-320.

http://dx.doi.org/10.1080/17405620544000048 
Natsuaki, M. N., Ge, X., Reiss, D., \& Neiderhiser, J. M. (2009). Aggressive behavior between siblings and the development of externalizing problems: Evidence from a genetically sensitive study. Developmental Psychology, 45, 1009-1018. http://dx.doi.org/10.1037/a0015698.

Noller, P. (2005). Sibling relationships in adolescence: Learning and growing together. Personal Relationships, 12, 1-22. http://dx.doi.org/10.1111/j.1350-4126.2005.00099.x

Oliva, A., \& Arranz, E. (2005). Sibling relationships during adolescence. European Journal of Developmental Psychology, 2(3), 253-270. http://dx.doi.org/10.1080/17405620544000002.

Onat-Zoyan, E. (2005). Determination the sibling relationships of people who have handicapped and non-handicapped siblings. Unpublished MS Thesis. Abant İzzet Baysal Üniversitesi. Sosyal Bilimler Enstitüsü. Özel Eğitim Ana Bilim Dalı. Bolu.

Öz, F. S. (2015). An adaptation, validity and reliability of the life span sibling relationship scale to the Turkish adolescents . Educational Research and Reviews, 10(2), 203-209. http://dx.doi.org/10.5897/ERR2014.2006.

Padilla-Walker, L. M., Harper, J. M., \& Jensen, A. C. (2010). Self-regulation as a mediator between sibling relationship quality and early adolescents' positive and negative outcomes. Journal of Family Psychology, 24(4), 419-428. http://dx.doi.org/10.1037/a0020387.

Pike, A., Coldwell, J., \& Dunn, J. F. (2005). Sibling relationships in early/middle childhood: Links with individual adjustment. Journal of Family Psychology, 19, 523-532. http://dx.doi.org/10.1037/0893-3200.19.4.523.

Richmond, M. K., Stocker, C. M., \& Rienks, S. L. (2005). Longitudinal associations between sibling relationships quality, parental differential treatment, and children's adjustment. Journal of Family Psychology, 19, 550-559. http://dx.doi.org/10.1037/0893-3200.19.4.550.

Riggio, H. R. (2000). Measuring attitudes toward adult sibling relationships: The life span sibling relationship scale. Journal of Social and Personal Relationships, 17, 707-728. http://dx.doi.org/10.1177/0265407500176001

Riggio, H. R. (2006).Structural features of sibling dyads and attitudes toward sibling relationships in young adulthood. Journal of Family Issues, 27(9), 1233-1254. http://dx.doi.org/10.1177/0192513X06289103.

Ross, H. S. (1996). Negotiating principles of entitlement in sibling property disputes. Developmental Psychology, 32, 90-101. http://dx.doi.org/10.1037/0012-1649.32.1.90

Sanders, R. (2004). Sibling relationships: Theory and issues for practice. Hampshire: Palgrave MacMillan.

Scholte, R. H. J., Poelen, E. A. P., Willemsen, G., Boomsma, D. I., \& Engels, R. C. M. E. (2008). Relative risks of adolescent and young adult alcohol use: The role of drinking fathers, mothers, siblings, and friends. Addictive Behaviors, 33, 1-14. http://dx.doi.org/10.1016/j.addbeh.2007.04.015

Slomkowski, C., Rende, R., Novak, S., Lloyd- Richardson, E., \& Niaura, R. (2005). Sibling effects on smoking in adolescence: Evidence for social influence from a genetically informative design. Addiction, 100, 430-438. http://dx.doi.org/10.1111/j.1360-0443.2004.00965.x

Stocker, C. M., Burwell, R. A., \& Briggs, M. L. (2002). Sibling conflict in middle childhood predicts children's adjustment in early adolescence. Journal of Family Psychology, 16, 50-57. http://dx.doi.org/10.1037/0893-3200.16.1.50

Teti, D. M. (2002). Retrospect and prospect in the psychological study of sibling relationships. In J. P. McHale \&W. S. Grolnick (Eds.), Retrospect and prospect in the psychological study of families (pp. 193-224). Mahwah, NJ: Lawrence Erlbaum

Tucker, C. J., Barber, B. L., \& Eccles, J. S. (1997). Advice about life plans and personal problems in late adolescent siblings relationships. Journal of Youth and Adolescence, 26, 63-76. http://dx.doi.org/10.1023/A:1024540228946.

Tucker, C. J., McHale, S, M., \& Crouter, A. C. (2001). Conditions of sibling support in adolescence. Journal of Family Psychology, 15, 254-271. http://dx.doi.org/10.1037/0893-3200.15.2.254.

Tucker, C. J., Updegraff, K. A., McHale, S. M., \& Crouter, A. C. (1999). Older siblings as socializers of younger siblings' empathy. Journal of Early Adolescence, 19, 176-198. http://dx.doi.org/10.1177/0272431699019002003

Updegraff, K. A., McHale, S. M., \& Crouter, A. C. (2002). Adolescents' sibling relationship and friendship.

Vogt, Y., A. S. (2009). Sibling relationships and adolescents' mental health: The interrelationship of structure and quality. Journal of Family Issues, 30, 1221-1244. http://dx.doi.org/10.1177/0192513X09334906. 
Voorpostel, M., \& Van der Lippe, T. (2007). Support between siblings and between friends: Two worlds apart? Journal of Marriage and Family, 69, 1271-1282. http://dx.doi.org/10.1111/j.1741-3737.2007.00446.x

Wheeler, K. M. (2012). Sibling group cohesion: A definition, validation and power in predicting perceived personal achievement. Unpublished Doctoral Thesis. The University of Texas, Austin, USA.

Whiteman, S. D., McHale, S. M., \& Crouter, A. C. (2007). Competing processes of sibling influence: Observational learning and sibling deidentification. Social Development, 16, 642-661. http://dx.doi.org/10.1111/j.1467-9507.2007.00409.x

Widmer, E. D., \& Weiss, C. C. (2000). Do older siblings make a difference? The effects of older sibling support and older sibling adjustment on the adjustment of socially disadvantaged adolescents. Journal of Research on Adolescence, 10, 1-27. http://dx.doi.org/10.1207/SJRA1001_1

Yeh, H. C., \& Lempers, J. D. (2004). Perceived sibling relationships and adolescent development. Journal of Youth and Adolescence, 33(2), 133-147. http://dx.doi.org/10.1023/B:JOYO.0000013425.86424.0f

\section{$(\mathrm{cc}) \mathrm{Br}$}

This work is licensed under a Creative Commons Attribution 3.0 License. 